Revista Médica Sinergia

Vol. 6, Núm. 8, agosto 2021, e695 https://doi.org/10.31434/rms.v6i8.695

revistamedicasinergia@gmail.com

\title{
Generalidades sobre encefalitis viral aguda
}

Overview of acute viral encephalitis

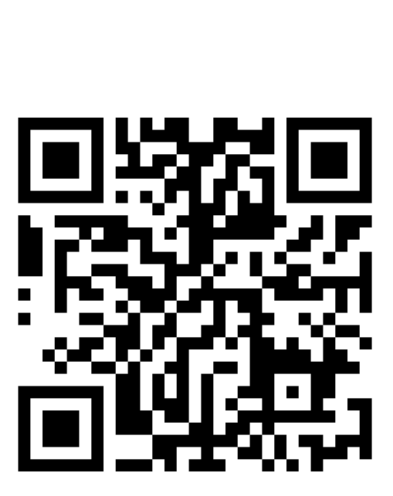

Recibido 24/05/2021

\author{
${ }^{1}$ Dra. Gloriana Pizarro Alvarado \\ Investigadora independiente, Heredia, Costa Rica \\ (D) https://orcid.org/0000-0002-9178-2751
}

${ }^{2}$ Dr. Juan Carlos Garnier Fernández Investigador independiente, San José, Costa Rica

(iD) https://orcid.org/0000-0002-5716-4562

${ }^{3} \mathrm{Dr}$. Roberto Orozco García Investigador independiente, Alajuela, Costa Rica https://orcid.org/0000-0003-4641-5001

Corregido 06/06/2021
Aceptado

20/06/2021

\section{RESUMEN}

La encefalitis es una inflamación del parénquima cerebral asociado a disfunción neurológica. Se suele presentar como un cuadro agudo o subagudo, con alteración del estado mental mayor de 24, fiebre, convulsiones, cefalea, y/o déficits neurológicos focales.

El Virus de herpes simple tipo 1 es la causa no epidémica más común de encefalitis infecciosa y la encefalitis japonesa es la causa más común de encefalitis infecciosa a nivel mundial. El pilar fundamental para el diagnóstico se basa en realizar una punción lumbar en la cual se observa pleocitosis linfocítica y se debe solicitar una PCR de manera urgente.

El tratamiento se basa en medidas de soporte asegurando la oxigenación, protección de las vías respiratorias, apoyo circulatorio, tratamiento de la pirexia y se recomienda iniciar de manera empírica con aciclovir intravenosa.

PALABRAS CLAVE: encefalitis viral; herpes simple virus; punción lumbar; aciclovir; diagnostico; pronostico; tratamiento.

\section{ABSTRACT}

Encephalitis is an inflammation of the brain parenchyma associated with neurological dysfunction. It usually presents as acute or subacute, with altered mental status greater than 24 hours, fever, seizures, headache, and/or focal neurologic deficits.

Herpes simplex virus type 1 is the most common non-epidemic cause of infectious encephalitis, and Japanese encephalitis is the most common cause of infectious encephalitis worldwide. The 
cornerstone for diagnosis is based on performing a lumbar puncture in which lymphocytic pleocytosis is observed and a PCR should be requested urgently.

Treatment is based on support measures ensuring oxygenation, airway protection, circulatory support, treatment of pyrexia and it is recommended to start empirically with intravenous acyclovir.

KEYWORDS: viral encephalitis; herpes simplex virus; acyclovir; lumbar puncture; diagnosis; prognosis; treatment.

${ }^{1}$ Médica general, graduada de la Universidad de Iberoamérica (UNIBE). Cód. MED16722. Correo: gloripa17@gmail.com

${ }^{2}$ Médico general, graduado de la Universidad de Iberoamérica (UNIBE). Cód. MED16727. Correo: juankgarnier@gmail.com

${ }^{3}$ Médico general, graduado de la Universidad de Iberoamérica (UNIBE). Cód. MED16746. Correo: rob.orozco.garcia@gmail.com

\section{INTRODUCCIÓN}

La encefalitis es una inflamación del parénquima cerebral asociado a disfunción neurológica y que puede deberse a una gran variedad de causas tanto infecciosas como autoinmunes (1). Las causas infecciosas constituyen aproximadamente el $50 \%$ de las etiologías identificables, siendo las más frecuentes y entre ellas, el virus herpes simple 1 (HSV-1) es la causa más frecuente de encefalitis esporádica a nivel mundial (2). Es una patología que requiere gran sospecha diagnostica, por su gran similitud con otras patologías que afectan el sistema nervioso central, donde se requiere la punción lumbar como principal método diagnóstico para la examinación del líquido cefalorraquídeo (LCR) y sus características; así como estudios de imágenes, donde la resonancia magnética resulta el principal estudio diagnóstico, debido a que esta es anormal en un $80-100 \%$ de los casos (3) representado una alta sensibilidad diagnostica en conjunto con los otros elementos del abordaje.

Tiene una prevalencia a nivel mundial, con una incidencia mundial de 1.7-12.6 casos por cada 100.000 mil habitantes anualmente $(1,4)$. Representa una causa importante de morbimortalidad si no realiza un diagnóstico temprano, donde aquellos pacientes con encefalitis viral por HSV sin tratamiento antiviral tienen una mortalidad del $70 \%$, donde menos de un $10 \%$ de los sobrevivientes regresan a su función neurológica basal $(2,5)$.

Las tasas de mortalidad han disminuido con el avance de los métodos diagnósticos y tratamiento empírico con aciclovir, sin embargo; al tratarse de una enfermedad con una prevalencia mundial y una mortalidad nada despreciable, las revisiones bibliográficas permiten valorar la bibliografía más reciente sobre el tema, con el objetivo de mantener actualizado a los profesionales sobre el diagnóstico temprano y manejo integral de la patología.

\section{MÉTODO}

Para elaboración de este artículo, la bibliografía fue tomada de diferentes bases de datos como Pubmed, Cochrane, Trip Medical Data Base y UpToDate, todas publicadas con 5 años 0 menos de antigüedad.

Los términos que se utilizaron fueron "encefalitis", "viral", "aciclovir", "diagnostico", "manejo", "pronóstico". Se realizó la revisión con la finalidad de obtener la información más actualizada en el tema, la bibliografía utilizada fue en idioma inglés en su totalidad.

\section{EPIDEMIOLOGÍA}

Hasta 12.6 pacientes por cada 100.000 individuos son afectados anualmente por la 
encefalitis, donde la mayor incidencia es en la población pediátrica, Las principales causas identificables son las virales, donde el virus de la encefalitis japonesa (JEV) es la causa epidémica más común (6) y el HSV es la causa esporádica para frecuentemente identificada entre $50-75 \%$ de los casos, los casos restantes divididos entre virus varicela - zoster (VZV), enterovirus y arbovirus $(1,7)$. En general, las causas virales representan un $50 \%$ de casos con etiología definida (2) donde el porcentaje restante corresponde a causas autoinmunes en un $20 \%$ y el resto no son identificadas a pesar de un amplio abordaje diagnóstico (1).

La encefalitis por HSV es causada casi de manera exclusiva por el HSV-1, a excepción de la población neonatal, donde el HSV-2 predomina, el otro grupo donde el HSV-2 se presenta es aquellos con inmunosupresión $(8,9)$. La infección por HSV-1 tiene una prevalencia de seropositividad en adultos mayores, de alrededor de un $60-90 \%(2,8)$.

La incidencia de encefalitis por HSV es de 24 casos por cada 1.000.000 de habitantes en un año (10), donde se presenta una distribución bimodal, con un pico de incidencia en aquellos menores de 3 años y otro pico de incidencia en adultos mayores de 50 años, donde la edad promedio es de 58 años, ambos sexos afectados de igual manera $(2,5)$. La encefalitis puede resultar tanto de la infección primaria como de la reactivación viral (9).

Los casos de encefalitis causados por arbovirus tienen una característica especial, $y$ es que, requieren la interacción de al menos dos especies no humanas para que el humano se vea infectado, donde un hospedero reservorio mantiene el virus en el ambiente y un vector que es el encargado de la transmisión del mismo. En Estados Unidos el virus West Nile causa entre 10002500 casos anuales, con una gran estacionalidad según la disponibilidad del vector (11).

\section{ETIOLOGÍA}

Las etiologías más comunes de la encefalitis son infecciosas, autoinmunes $y$ postinfecciosas.

Los virus son los organismos más frecuentes que causan encefalitis infecciosa (9).

El VHS representa entre el 50 y el $75 \%$ de los casos virales identificados, es la causa no epidémica más común de encefalitis infecciosa en la mayoría de los países desarrollados $(7,9,12)$.

La encefalitis por VHS está en la mayoría de ocasiones asociada al virus de VHS-1, el cual se presenta en un $95 \%$ de los casos, excepto en las poblaciones neonatales donde predomina el VHS-2 $(9,12)$.

EI VZV es la segunda causa más común de encefalitis vírica después del VHS. (9)

Dentro del grupo de los herpes virus además se encuentran; la encefalitis por el virus de Epstein-Barr (VEB) que suele darse durante la primo infección y también la infección por el herpesvirus humano tipo 6 que se produce en la mayoría de los individuos del mundo antes de los 2 años de edad y en adultos que cuentan con inmunosupresión (9).

Los arbovirus son una gran familia de virus transmitidos por vectores artrópodos, siendo los principales los mosquitos $y$ las garrapatas $(9,13)$.

El virus del Nilo Occidental es en este momento la causa más común demostrada de encefalitis viral epidémica en los Estados Unidos y es el arbovirus más frecuente que causa encefalitis en América del Norte (13). La JEV es la causa más común de encefalitis infecciosa a nivel mundial, y se da en el sur y el este de Asia (6).

Otros agentes responsables de ocasionar encefalitis viral son el virus del dengue, del zika y chikungunya .

El virus del dengue se observa de manera común en la India, China, el sudeste asiático, África y América Central y del Sur. El virus del chikungunya tiene una distribución geográfica similar a la del virus del dengue $(1,12)$. 


\section{CLÍNICA}

La encefalitis suele presentarse como un cuadro agudo o subagudo, usualmente mayor de 24 horas de alteración del estado mental, asociado a fiebre, aparición de actividad convulsiva de nueva aparición, cefalea, y/o déficits neurológicos focales; los hallazgos neurológicos suelen ser agudos (menores de una semana de evolución) y puede incluir: hemiparesia, disfasia, afasia, ataxia. Un $90 \%$ de los pacientes va a presentar fiebre asociado a uno de los síntomas previamente descritos $(6,9,10)$.

Sin embargo, las manifestaciones clínicas especificas van a depender de la parte específica del parénquima cerebral que se vea afectada, y esto, puede guiar la sospecha diagnostica a una etiología específica, por ejemplo, es frecuente observar brote cutáneo en los casos de encefalitis por enterovirus, parotiditis asociados a infección por paperas, una infección del tracto respiratorio superior concurrente al pensar en influenza, los pacientes con rabia tiene un hallazgo clínico característico de presentar hidrofobia o aerofobia, así como, una parálisis ascendente que puede simular al síndrome de Guillain-Barré; el JEV se asocia con extrapiramidalismo prominente así como, rigidez y movimientos anormales sugestivos de alteración de ganglios basales (6).

En el caso de la encefalitis por HSV, la sospecha clínica debe ser mayor, esto por la importancia del inicio del tratamiento empírico temprano, no existen signos o síntomas patognomónicos de la enfermedad, suelen presentar síntomas prodrómicos que incluyen: cefalea, cambios en el comportamiento $y$ alucinaciones olfatorias. Con fiebre, cefalea y focalizaciones neurológicas como las descritas previamente, las convulsiones se presentan en un $50 \%$ de los casos. Los signos meníngeos suelen estar ausentes y la depresión en el nivel de conciencia puede avanzar rápidamente, hasta alcanzar el coma en $1 / 3$ de los pacientes $(5,9)$.

\section{DIAGNÓSTICO}

La alteración del estado de conciencia es una presentación clínica muy frecuente en los servicios de urgencias y presenta un gran diagnostico diferencial; es un reto distinguir las diferentes causas de encefalopatía, como: séptica, metabólica, toxica y otras de aquellos pacientes con encefalitis, que requieren un tratamiento específico que debe ser iniciado lo antes posible (14).

Se utilizan los siguientes criterios para sospechar encefalitis, son paciente con cuadro de alteración persistente del estado de conciencia mayor a 24 horas, incluidos: letargia, irritabilidad o alteración de personalidad y comportamiento; asociado a 2 o más de las siguientes: fiebre, convulsiones y/o focalizaciones neurológicas no atribuibles a otra causa, pleocitosis en el LCR, hallazgos sugestivos en neuroimágenes y alteraciones sugestivas en el electroencefalograma $(9,14)$.

En todos los casos de sospecha de encefalitis viral es clave obtener de manera rápida una muestra de LCR, por lo que, la punción lumbar se debe obtener de manera urgente y no debe ser retrasada por estudios de neuroimagen, a menos que existan contraindicaciones específicas, tales como: focalizaciones neurológicas, papiledema, convulsiones persistentes, posturas anormales, bradicardia relativa con hipertensión, escala de Glasgow menor a 12 puntos, con la finalidad de descartar herniación, lesiones espacio ocupantes y edema cerebral $(1,14)$. La tomografía axial computarizada suele ser el método que se utilizar, ya que confiere una rápida evaluación, sin embargo, tiene baja sensibilidad para detectar anormalidades sugestivas de encefalitis, especialmente en el inicio del cuadro clínico, si están 
presenten, se pueden observar lesiones hipodensas, típicamente en lóbulos temporales (2).

La punción lumbar sugestiva de la encefalitis viral, suele demostrar una pleocitosis (más de 5 leucocitos $\left.\times 10^{9} / \mathrm{L}\right)$, de predominio linfocitario, sin embargo, temprano en la evolución del cuadro clínico pueden predominar los neutrófilos; las proteínas suelen normales o moderadamente elevadas (usualmente menos de $150 \mathrm{mg} / \mathrm{dL}$ ) y la glucosa normal (mayor del $50 \%$ del valor sérico) $(13,14)$. Siendo la causa esporádica más frecuente de encefalitis, se debe realizar siempre una reacción en cadena de polimerasa (PCR) de ADN para HSV-1 y HSV-2 del LCR, siendo el mejor estudio diagnóstico, con una sensibilidad del $98 \%$ y especificidad del $99 \%$, puede ocurrir que temprano en el curso clínico sea negativa en un $0.4 \%$ de los pacientes, sin embargo, se debe repetir a los 3-4 días de inicio de síntomas neurológicos; si la primera punción lumbar es negativa, pero la clínica y las imágenes son altamente sugestivas, se debe iniciar de igual manera el tratamiento empírico con aciclovir. También se deben obtener PCR para VZV y enterovirus, otros diagnósticos específicos se deben agregar según la geográfica y la historia clínica $(2,10,15,16)$.

La resonancia magnética con o sin contraste es el estudio de elección para evaluar la encefalitis, especialmente aquella causada por HSV, la cual tiene alta sensibilidad y, es anormal en un $80-100 \%$ de los casos, sin embargo, imágenes normales, no descartan el diagnostico $(10,15)$. La encefalitis por HSV afecta con mayor frecuencia el lóbulo temporal medial de manera unilateral en un $64-68 \%$ de los casos, puede afectar también, la cortea frontobasal, y muestra típicamente hiperintensidades en la corteza y la materia blanca en T2 y FLAIR. En la parte aguda de la enfermedad la técnica por difusión (DWI) es más sensible para detectar lesiones, y muestra típicamente restricción en la difusión.

El electroencefalograma es anormal en un $80 \%$ de los casos de encefalitis viral por HSV, y muestra ondas lentas de amplitud alta, asociado a descargas epileptiformes periódicas originadas en el lóbulo temporal afectado, sin embargo, son cambios no específicos, que deben ser correlacionados con la clínica y los otros métodos diagnósticos (5).

\section{MANEJO}

Los pacientes con encefalitis son enfermos agudos y requieren tratamiento médico de apoyo y los casos graves deben ser tratados en una unidad de cuidados intensivos.

Este tipo de pacientes requiere una monitorización intensa, y se debe asegurar en la evaluación inicial la oxigenación, protección de las vías respiratorias, apoyo circulatorio, tratamiento de la pirexia y las arritmias cardíacas. Además, se debe tratar los efectos de la inflamación cerebral como son el edema, el aumento de la presión intracraneana y las convulsiones que pueden ser focales o generalizadas $(6,7,11)$. Existen varias medidas de apoyo que se recomiendan, entre estas están el reducir la temperatura corporal mediante el uso de antipiréticos y métodos de enfriamiento.

Además, se debe hidratar de manera adecuada al paciente para tener una adecuada circulación y mantener un estado hidroelectrolítico y ácido-base en rangos normales.

Las crisis convulsivas se tratan de mejor manera con anticonvulsivantes por vía intravenosa como el valproato o la fenitoína $(6,7,16)$.

Cuando hay elevación de la presión intracraneana, se puede utilizar una infusión de manitol $(0,25$ a $1,0 \mathrm{mg} / \mathrm{kg}$ cada 4 a 6 horas) o furosemida intravenosa. También puede usarse la hiperventilación para mantener la presión arterial de dióxido de 
carbono (CO2) entre 25 y $30 \mathrm{mmHg}$ y combatir el aumento de la presión intracraneana. En caso de aumento rápido de la tensión intracraneal, la descompresión quirúrgica puede salvar la vida del paciente. El uso de los corticoides es controversial, ya que se podrían utilizar para aliviar la hipertensión intracraneana, pero existe el riesgo de que la infección vírica se agudice con los esteroides $(6,16)$.

La solución salina hipertónica (3\%) en una dosis de 0,1 a $1 \mathrm{~mL} / \mathrm{kg}$ por hora para mantener el sodio sérico entre 145 y 155 $\mathrm{mEq} / \mathrm{L}$ es otra opción.

Por último, se pueden presentar sangrados digestivos como consecuencia de úlceras de estrés, por lo que debe ser manejado con antihistamínicos, antiácidos, ranitidina y si es necesario una transfusión de sangre (6).

Posterior a las medidas de apoyo se debe dar un tratamiento específico dirigido a la causa más frecuente. Debido a la frecuencia y a la morbilidad y mortalidad asociadas con el tratamiento tardío de la encefalitis por VHS, debe iniciarse un tratamiento empírico con aciclovir con una dosis de $10 \mathrm{mg} / \mathrm{kg}$ por vía intravenosa cada 8 horas. En individuos con función renal alterada se debe disminuir la dosis, y se debe administrar durante 14 días en pacientes inmunocompetentes, y durante 21 días en pacientes inmunocomprometidos $(1,14,15)$.

En la encefalitis por VZV el tratamiento es con la misma dosis diaria de aciclovir que el VHS $30 \mathrm{mg} / \mathrm{kg} / \mathrm{día}$, en tres dosis divididas. La recomendación habitual es de 14 días de tratamiento.

Debido a la vasculitis que acompaña a la enfermedad, muchos expertos recomiendan el uso de corticosteroides complementarios, con una dosis de prednisona de $1 \mathrm{mg} / \mathrm{kg}$ diario, con una duración de 3 a 5 días $(11,12)$.

El foscarnet se utiliza en las encefalitis causadas por el $\mathrm{VHH}-6$ con una dosis de 60 $\mathrm{mg} / \mathrm{kg}$ cada 8 horas $(1,11)$.
El tratamiento de los pacientes infectados por el VEB está dirigido a la restauración de las células $T$. La terapia antiviral, incluyendo el aciclovir, muestra actividad in vitro por lo que se recomienda este medicamento.

El tratamiento sintomático es el sello distintivo del tratamiento de las infecciones por arbovirus y enterovirus.

El manejo para el Virus del dengue, el zika y el chikungunya consiste principalmente en la atención de los síntomas y se centra en el equilibrio adecuado de los líquidos.

\section{PRONÓSTICO}

El pronóstico de la encefalitis viral a pesar de los nuevos métodos diagnósticos, continúa siendo generalmente malo con una mortalidad aproximada del 5-15\%; y aquellos que sobreviven un $68 \%$ lo hacen sin secuelas, un $18 \%$ con secuelas leves, un $14 \%$ con secuelas severas y $1 \%$ en estado vegetativo, existen predictores de mal pronóstico, que incluyen: paciente con inmunosupresión, escala de Glasgow $\leq 8$, necesidad de ingresar a unidad de cuidados intensivos, edad mayor a 65 años $(1,7,13)$.

Con respecto a la encefalitis por HSV específicamente, previo al uso del aciclovir, la tasa de mortalidad era de hasta $70 \%$, sin embargo, desde el inicio del tratamiento empírico oportuno, esta tasa se ha logrado reducir hasta $20-30 \%$, la cual es persistentemente alta, y usualmente con secuelas neurológicas en los sobrevivientes, suelen asociar anormalidades severas del comportamiento, amnesia anterógrada y deterioro cognitivo severo, con frecuencia se documenta disnomia y dificultad para aprender material tanto verbal como visual, donde menos de un $10 \%$ de los paciente retorna a su función neurológica basal $(5,10,15)$.

El pronóstico suele ser más reservado en aquellos pacientes adultos mayores e inmunosupresos, al igual que en los casos causados por HSV-2, siendo el factor de 
peor pronóstico el retraso en el inicio del tratamiento antiviral con aciclovir mayor a 24 horas desde el ingreso hospitalario, el mejor pronostico se ha documentado en aquellos pacientes que se inicia el aciclovir temprano en el curso de la enfermedad, previo al desarrollo de necrosis extensa del lóbulo temporal, el cual corresponde al deterioro del nivel de conciencia; Por lo que, uno de las principales limitantes en el manejo de la patología es el retraso en el inicio del tratamiento antiviral, donde según múltiples estudios, el retraso promedio es usualmente mayor a 48 horas posterior al ingreso hospitalario, lo que lleva a tasas mayores de morbimortalidad, por esta razón, se debe mantener un alto índice de sospecha y un umbral muy bajo para iniciar el tratamiento empírico con aciclovir (15).

\section{CONCLUSIONES}

La encefalitis viral es una enfermedad con alta prevalencia a nivel mundial y con una etiología variada que se presenta según la zona geográfica, la estación, el contacto con vectores y las características de los pacientes. $Y$ de aquí radica la importancia de realizar una historia clínica y un examen físico minucioso para lograr descifrar el agente etiológico

Es de suma importancia lograr reconocer esta enfermedad y darle el tratamiento oportuno ya que es una patología con tasas altas de mortalidad y secuelas importantes si no se suministra de manera pronta la terapia correspondiente.

El tratamiento es en su mayoría empírico y sintomático por lo que se requieren más investigaciones futuro para prevenir y tratar esta patología.

\section{Los autores declaran no tener conflicto de interés.}

\section{REFERENCIAS}

1. Venkatesan A, Michael BD, Probasco JC, Geocadin RG, Solomon T. Acute encephalitis in immunocompetent adults. The Lancet. febrero de 2019;393(10172):702-16.

2. Bradshaw MJ, Venkatesan A. Herpes Simplex Virus-1 Encephalitis in Adults: Pathophysiology, Diagnosis, and Management. Neurotherapeutics. julio de 2016;13(3):493-508

3. Bertrand A, Leclercq D, Martinez-Almoyna L, Girard N, Stahl J-P, De-Broucker T. MR imaging of adult acute infectious encephalitis. Médecine Mal Infect. mayo de 2017;47(3):195-205.

4. Beaman MH. Community-acquired acute meningitis and encephalitis: a narrative review. Med J Aust. noviembre de 2018;209(10):449-54.

5. Gnann JW, Whitley RJ. Herpes Simplex Encephalitis: an Update. Curr Infect Dis Rep. marzo de 2017;19(3):13.

6. Kumar R. Understanding and managing acute encephalitis. F1000Research. 29 de enero de 2020;9:60.

7. Tyler KL. Acute Viral Encephalitis. Ropper AH, editor. $\mathrm{N}$ Engl J Med. 9 de agosto de 2018;379(6):557-66.

8. Rabinstein AA. Herpes Virus Encephalitis in Adults. Neurol Clin. noviembre de 2017;35(4):695705.

9. Venkatesan A, Murphy OC. Viral Encephalitis. Neurol Clin. noviembre de 2018;36(4):705-24.

10. Klein RS. Herpes simplex virus type 1 encephalitis. :21.

11. Halperin JJ. Diagnosis and management of acute encephalitis. En: Handbook of Clinical Neurology [Internet]. Elsevier; 2017 [citado 22 de mayo de 2021]. p. 337-47. Disponible en: https://linkinghub.elsevier.com/retrieve/pii/B9780 444636003000180

12. Bookstaver PB, Mohorn PL, Shah A, Tesh LD, Quidley AM, Kothari R, et al. Management of Viral Central Nervous System Infections: A Primer for Clinicians. J Cent Nerv Syst Dis. 1 de enero de 2017;9:117957351770334.

13. Gluckman SJ. Viral encephalitis in adults. :22.

14. Ellul M, Solomon T. Acute encephalitis - diagnosis and management. Clin Med. abril de 2018;18(2):155-9.

15. Stahl JP, Mailles A. Herpes simplex virus encephalitis update: Curr Opin Infect Dis. junio de 2019;32(3):239-43.

16. León Alvarado LJ, Franco Olivo NS, Sánchez Acebo JA, Borja Viteri MA. Manejo de la encefalitis y la meningitis. RECIAMUC. 30 de enero de 2021;5(1):368-81. 